\title{
Association Between Obesity and Cigarette Smoking: A Community-Based Study
}

\author{
Ibrahim A. Ginawi ${ }^{\mathrm{a}}$, Abdelhafiz Ibrahim Bashira, Yaser Quayed Alreshidia ${ }^{\mathrm{a}}$, Ahmed Dirweesh ${ }^{\mathrm{b}}$, \\ Awdah M. Al-Hazimic ${ }^{\text {, Hussain Gadelkarim Ahmed }}{ }^{\text {a }}$, Ehab Kamald ${ }^{\text {, Mohamed H. Ahmed }}{ }^{\text {e, }}$
}

\begin{abstract}
Background: Cigarettes smoking and obesity are major public health problems and leading causes of preventable morbidity and mortality worldwide. The aim of this study was to investigate the relationship between cigarettes smoking and body weight status among Northern Saudi subjects.
\end{abstract}

Methods: Data were collected during cross-sectional survey which included 5,000 Saudi selected from 30 primary health care centers (PHCs) in Hail Region.

Results: The overall prevalence of obesity in Hail was $36.9 \%$. The prevalence of cigarettes smoking was $10.2 \%$. In those who are current smokers, obesity was present in $24.9 \%$, normal weight in $30.9 \%$ and overweight in $7.4 \%$. In those who are ex-smokers, obesity was present in $45.0 \%$, normal weight in $20.3 \%$ and overweight in $31.3 \%$. In those who never smoked, obesity was present in $27.6 \%$, normal weight in $32.8 \%$ and overweight in $37.3 \%$.

Conclusion: Obesity was most prevalent among ex-smokers and least prevalent among current smokers. It is clear that from the analyses, the group of current smokers were less likely to be obese in comparison with never smokers and ex-smokers were more likely to be obese than both current smokers and never smokers.

Keywords: Smoking; Obesity; Association; Community

\section{Introduction}

It is very likely that the use of tobacco emerged many thou-

Manuscript accepted for publication September 23, 2016

${ }^{a}$ College of Medicine, University of Hail, Hail, Saudi Arabia

bSeton Hall University, St. Francis Medical Center, Trenton, NJ, USA

${ }^{\mathrm{c}}$ College of Medicine, King Abdulaziz University, Jeddah, KSA

${ }^{\mathrm{d}}$ King Fahad Specialist Hospital, Accident \& Emergency Department, Buraidah, KSA

eDepartment of Medicine, Milton Keynes University Hospital NHS Foundation Trust, Eaglestone, Milton Keynes, Buckinghamshire, UK

${ }^{f}$ Corresponding Author: Mohamed H. Ahmed, Department of Medicine, Milton Keynes University Hospital NHS Foundation Trust, Eaglestone, Milton Keynes, Buckinghamshire, UK. Email: elziber@yahoo.com

doi: http://dx.doi.org/10.14740/jem378e sands years ago. There is considerable interest in the effect of smoking on obesity. Several studies have shown different impacts of smoking on obesity. Beside the fact that nicotine is associated with decreases in appetite and calorie intake, smoking also decreases capacity of individual to perform exercise due to impact on lung functions [1-3]. Due to the fact that smoking has different effects on obesity, different studies showed conflicting outcomes. For instance, it was shown that daily smokers are likely to be obese and put extra $6 \mathrm{~kg}$ of weight [4]. In a cross-sectional study of 6,123 individuals, cigarettes smoked per day were positively associated with central fat accumulation, particularly in women [5]. Importantly, smoking in employees of Austrian company was shown to be associated with an increase in body weight, low high density lipoprotein and higher fasting glucose [6]. Smoking was shown to induce distribution of body fat and can be associated with central obesity $[7,8]$. Age may have an impact on how weight and body fat distribution occurred. For instance, Su et al showed that for young men, smoking might have an effect on increasing fat free mass, body mass index (BMI) and waist circumference (WC), and decreasing fat mass and fat percentage. For middle-aged and older men, smoking might have an effect on decreasing fat free mass, fat mass, BMI, WC, and fat percentage and obesity is likely to occur in those enrolled in smoking cessation programs for those former smokers [9]. Other studies showed that smoking may not have an effect on weight or may be associated with weight loss. In another study, smoking has no effect on weight [10]. Several studies reported that smoking was associated with lower weights and BMI [11-13]. Smoking is also known to be associated with insulin resistance and type 2 diabetes [14-16]. To further study the relationship between smoking status and obesity in Saudi civilians, we performed a cross-sectional population-based study of Saudi adults, with multiple indicators such as BMI, age, sex and smoking status.

\section{Materials and Methods}

Data regarding obesity were collected as a part of a comprehensive survey that included 5,000 Saudi civilians living in Hail region, Northern Saudi Arabia, during the period from October 2012 to December 2013. The sample size was calculated to obtain confidence level of $95 \%$ and confidence interval of 1.38 . Participants were selected from 30/105 primary health care centers (PHCs) by simple random method. The primary care program in Saudi Arabia is a leading program in the developing countries that has accomplished respectable success within a 


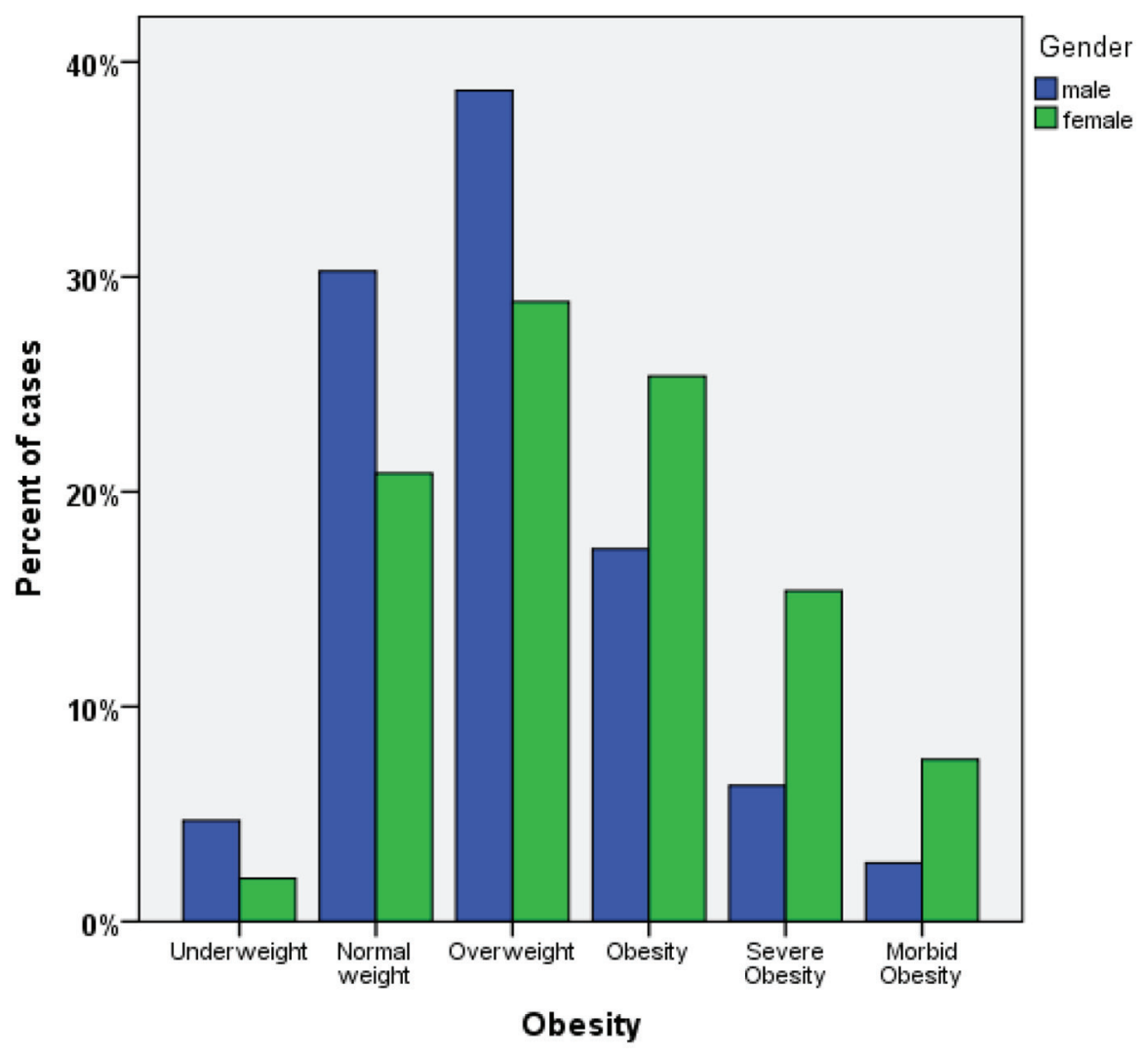

Figure 1. Association between obesity grade and gender.

few years of its establishment. The Ministry of Health $(\mathrm{MOH})$ provides PHC services throughout Hail region comprising 105 centers. Participants were recruited to the local PHC in each area before 1 week of the campaign. On campaign day, all responding individuals were included up to the target of 5,000 participants. The purpose of the survey was to estimate the prevalence of chronic kidney disease in the area. Data were collected by the doctors of the team utilizing a standard questionnaire, which included demographic information and previously diagnosed diseases (hypertension, diabetes, and others).

The data were analyzed using SPSS v20. ANOVA was used to compare the mean between groups and Chi-squared test was used to test association. A P value less than 0.05 was considered as significant. Data were presented as frequencies percent and means \pm standard error of mean.

\section{Results}

The mean age of the study population was $42.5 \pm 0.32$ years with $45.5 \pm 0.47$ for males and $42.9 \pm 0.41$ for females. Males to females ratio was 1.08:1.00.

The overall prevalence of obesity in Hail was $36.9 \%$. Moreover, the prevalence within the males was $26.4 \%$, while within the females it was $48.3 \%$. When categorizing obesity, $33.9 \%, 21.2 \%, 10.7 \%$, and $5 \%$ were categorized as overweight, obese, severely obese and with morbid obesity, respectively.
Moreover, increased weight categories were strongly linked to females and this was found to be statistically significant $(\mathrm{P}<$ 0.0001), as indicated in Figure 1.

\section{Association between obesity grade and gender}

Concerning the relation between age groups and obesity, we found that the prevalence of obesity of is more concentrated in the age group of $41-55$ of age. Within this group, the overall prevalence of obesity was $51.0 \%$ with $28.7 \%, 14.2 \%$ and $8.1 \%$ categorized as obese, severely obese, and morbidly obese, respectively. The second group affected is the age group of $26-40$ of age which also is higher in a category of overweight (Fig. 1).

An overall prevalence of obesity was $42.0 \%$ with $23.5 \%$, $13.6 \%$ and $5 \%$ categorized as obese, severely obese, and morbidly obese, respectively.

\section{Relation between obesity grade and age}

The prevalence of cigarettes smoking was $10.2 \%$. In those who are current smokers, obesity was present in $24.9 \%$, normal weight in $30.9 \%$ and overweight in $7.4 \%$. The prevalence of ex-smoking was $55.0 \%$. Among this group, obesity was present in $45.0 \%$, normal weight in $20.3 \%$ and overweight in $31.3 \%$. In those who never smoked, obesity was present in $27.6 \%$, nor- 


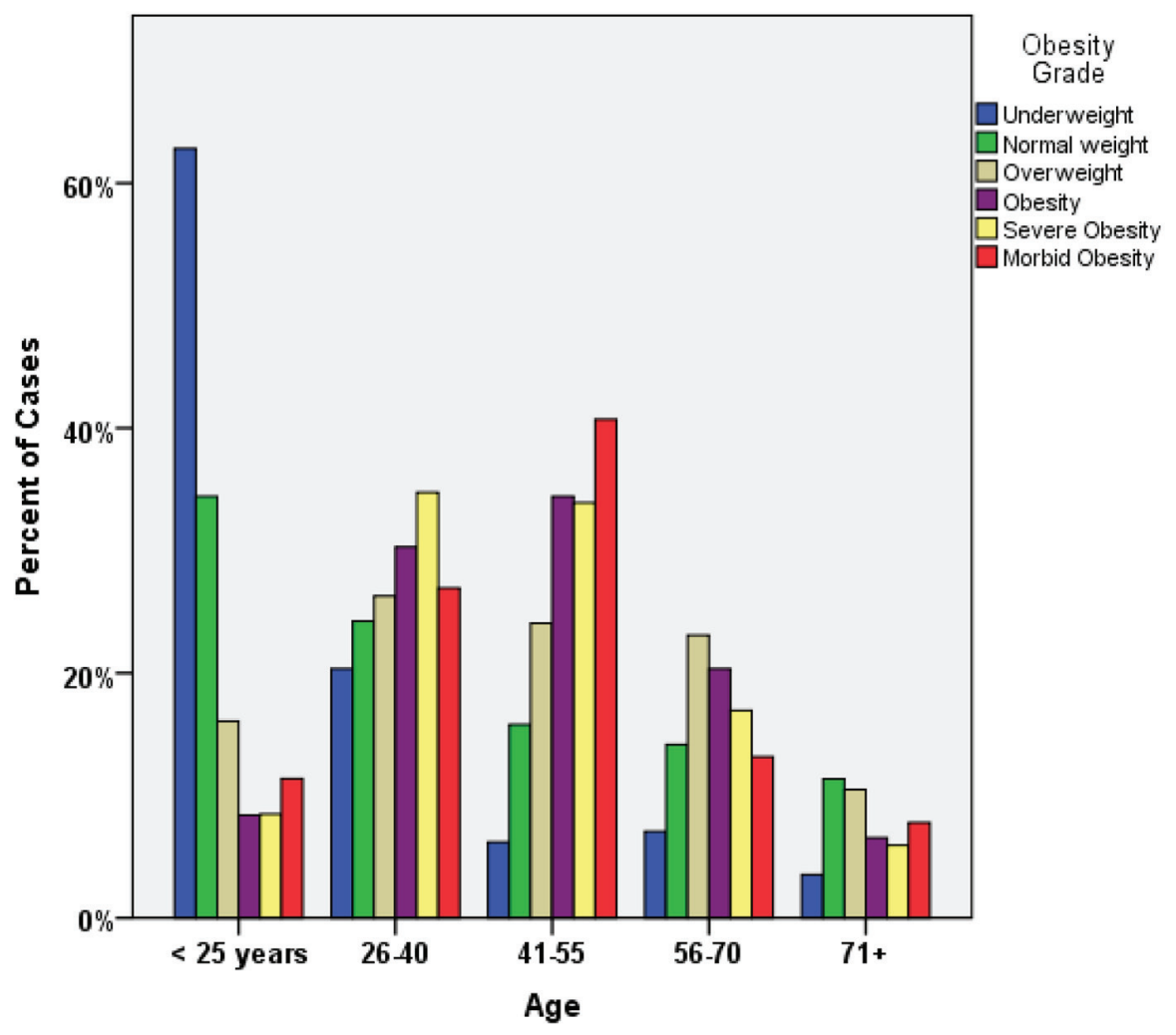

Figure 2. Relation between obesity grade and age.

mal weight in $32.8 \%$ and overweight in $37.3 \%$ (Fig. 2, Table $1)$. In this study, we found that obesity was significantly more prevalent among ex-smokers $(\mathrm{P}<0.05)$ and underweight was significantly associated with current smoking $(\mathrm{P}<0.05)$. The overall mean of BMI was $28.6 \pm 0.11$. The mean BMI values in the never smoke, ex-smoker, and current smokers were $27.5 \pm$ $0.17,29.7 \pm 0.15$, and $26.9 \pm 0.32$, respectively. BMI was found to be significantly higher in the ex-smokers group as compared with current smokers and never smoked group $(\mathrm{P}<0.05)$ (Fig. 3 ). The effect of ex-smoking on BMI and prevalence of obesity was found to be independent of the effects of age and gender.

\section{Discussion}

In this cross-sectional study, we have shown that obesity was most prevalent among ex-smokers and least prevalent among current smokers. Furthermore, current smokers were less likely to be obese in comparison with never smokers and ex-smokers were more likely to be obese than both current smokers and never smokers. Interestingly, it was shown that ex-smokers usually gain around 10 pounds of body weight within the first year of abstinence [17]. In meta-analysis, it was shown that smoking cessation is associated with a mean increase of $4-5 \mathrm{~kg}$ in body weight after 12 months of abstinence, and most weight gain occurs within 3 months of quitting. Variation in weight change is large, with about $16 \%$ of quitters losing weight and $13 \%$ gaining more than $10 \mathrm{~kg}$ [18]. It was shown that smokers with a high nicotine dependency are more likely to gain weight during smoking cessation therapy and they may require intervention against weight gain in the cessation clinic [19]. Several population studies have shown that smoking cessation is associated with an increase in body weight [20-22].

In this study, we have shown that smokers are unlikely to gain weight. Patel et al reported that, among both African American and Caucasian women, current smokers had

Table 1. Association Between Smoking Status and Obesity Grade

\begin{tabular}{|c|c|c|c|c|c|c|c|}
\hline \multirow{2}{*}{ Smoking status } & \multicolumn{6}{|c|}{ Obesity grade } & \multirow{2}{*}{ Total } \\
\hline & Underweight & Normal weight & Over weight & Obese & Severely obese & Morbidly obese & \\
\hline Never smoked & $27(2.3 \%)$ & $379(32.8 \%)$ & $430(37.3 \%)$ & $193(16.7 \%)$ & $96(8.3 \%)$ & $29(2.5 \%)$ & $1,154(100.0 \%)$ \\
\hline Current smoker & $25(7.4 \%)$ & $104(30.9 \%)$ & $124(36.8 \%)$ & $52(15.4 \%)$ & $23(6.8 \%)$ & $9(2.7 \%)$ & $337(100.0 \%)$ \\
\hline Total & $113(3.4 \%)$ & $854(25.7 \%)$ & $1,126(33.9 \%)$ & $703(21.2 \%)$ & $354(10.7 \%)$ & $167(5.0 \%)$ & $3,317(100.0 \%)$ \\
\hline
\end{tabular}




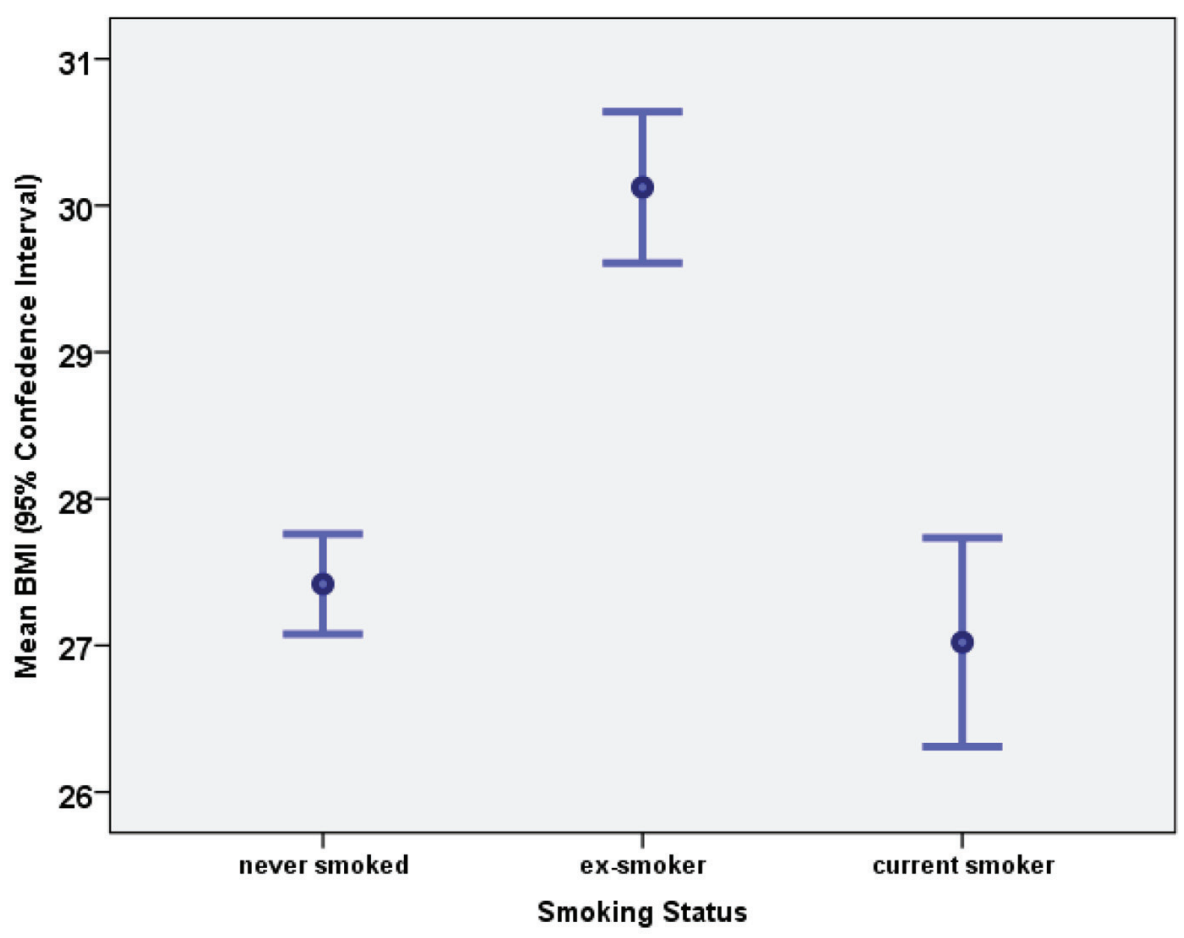

Figure 3. Association between smoking status and body mass index.

decreased odds of being overweight or obese compared to normal-weight non-smokers, and the inverse trends between current smoking and BMI held for both African American and white [23]. Two studies in China have shown that smoking is not associated with an increase in body weight. For instance, $\mathrm{Xu}$ et al reported that, among Chinese men, the prevalence of overweight (BMI) was significantly lower among current smokers than in non-smokers and former smokers. Interestingly, only male ex-smokers were at risk of central obesity $[13,24]$. While in a study in Korea, it was shown that in Korean adolescents, smoking frequency and cigarette consumption had positive effects with regard to weight loss [12]. Interestingly, in Caucasian men and women, current smokers had lower mean BMI, WC, and body fat percentage, compared with non-smokers. Age-adjusted mean WC and body fat increased with cigarettes smoked per day among smokers, while not significantly related to BMI [5]. Furthermore, among Austrian bank male and female employees, no differences in total body fat and/or body fat distribution were found among non-smokers, smokers and former smokers [6]. Despite the fact that obesity and smoking are very common in different communities across the globe, only $5 \%$ of general population smoke and are obese [24]. In this study, the overall prevalence of smoking was $10.2 \%$ and prevalence of smoking among obese individual was $6.9 \%$. Obesity is a well-known risk factor for insulin resistance and type 2 diabetes. Smoking is also associated with central obesity, insulin resistance, low high density lipoprotein and type 2 diabetes [7, 8, 13, 25]. Further research is needed to assess the prevalence of diabetes among obese smokers.

Our study has some limitations. This cross-sectional study may not represent the whole community. In addition, smoking is considered as social stigma among Saudi females. We have also not studied the presence of confounding factors that may affect obesity like physical activity, total calories intake and level of education. Finally, the relationship between cigarettes smoked per day and obesity was not studied. Despite these limitations, this is the first study in the North of Saudi Arabia to address the prevalence of obesity and smoking in this region.

\section{Conclusion}

Obesity was most prevalent among ex-smokers and least prevalent among current smokers.

\section{Conflicts of Interest}

None.

\section{References}

1. Stadler M, Tomann L, Storka A, Wolzt M, Peric S, Bieglmayer C, Pacini G, et al. Effects of smoking cessation on beta-cell function, insulin sensitivity, body weight, and appetite. Eur J Endocrinol. 2014;170(2):219-217.

2. Chen H, Vlahos R, Bozinovski S, Jones J, Anderson GP, Morris MJ. Effect of short-term cigarette smoke exposure on body weight, appetite and brain neuropeptide $\mathrm{Y}$ in 
mice. Neuropsychopharmacology. 2005;30(4):713-719.

3. Chen H, Hansen MJ, Jones JE, Vlahos R, Anderson GP, Morris MJ. Long-term cigarette smoke exposure increases uncoupling protein expression but reduces energy intake. Brain Res. 2008;1228:81-88.

4. Ward KD, Ahn S, Mzayek F, Al Ali R, Rastam S, Asfar T, Fouad F, et al. The relationship between waterpipe smoking and body weight: population-based findings from Syria. Nicotine Tob Res. 2015;17(1):34-40.

5. Clair C, Chiolero A, Faeh D, Cornuz J, Marques-Vidal P, Paccaud F, Mooser V, et al. Dose-dependent positive association between cigarette smoking, abdominal obesity and body fat: cross-sectional data from a populationbased survey. BMC Public Health. 2011;11:23.

6. de Oliveira Fontes Gasperin L, Neuberger M, Tichy A, Moshammer H. Cross-sectional association between cigarette smoking and abdominal obesity among Austrian bank employees. BMJ Open. 2014;4(7):e004899.

7. Barrett-Connor E, Khaw KT. Cigarette smoking and increased central adiposity. Ann Intern Med. 1989;111(10):783-787.

8. Shimokata H, Muller DC, Andres R. Studies in the distribution of body fat. III. Effects of cigarette smoking. JAMA. 1989;261(8):1169-1173.

9. Su P, Hong L, Sun H, Zhao YF, Li L. Age plays an important role in the relationship between smoking status and obesity risk: a large scale cross-sectional study of Chinese adults. Int J Clin Exp Med. 2015;8(10):18894-18906.

10. Wang Q. Smoking and body weight: evidence from China health and nutrition survey. BMC Public Health. 2015; $15: 1238$.

11. LaRowe TL, Piper ME, Schlam TR, Fiore MC, Baker TB. Obesity and smoking: comparing cessation treatment seekers with the general smoking population. Obesity (Silver Spring). 2009;17(6):1301-1305.

12. Jong-Hyuck K, Wi-Young S. Association of smoking frequency and cigarette consumption with obesity in Korean adolescents. Bratisl Lek Listy. 2012;113(10):599-603.

13. Fang H, Ali MM, Rizzo JA. Does smoking affect body weight and obesity in China? Econ Hum Biol. 2009;7(3):334-350.

14. Attvall S, Fowelin J, Lager I, Von Schenck H, Smith
U. Smoking induces insulin resistance - a potential link with the insulin resistance syndrome. J Intern Med. 1993;233(4):327-332.

15. Eliasson B, Taskinen MR, Smith U. Long-term use of nicotine gum is associated with hyperinsulinemia and insulin resistance. Circulation. 1996;94(5):878-881.

16. Xie XT, Liu Q, Wu J, Wakui M. Impact of cigarette smoking in type 2 diabetes development. Acta Pharmacol Sin. 2009;30(6):784-787.

17. Audrain-McGovern J, Benowitz NL. Cigarette smoking, nicotine, and body weight. Clin Pharmacol Ther. 2011;90(1):164-168.

18. Aubin HJ, Farley A, Lycett D, Lahmek P, Aveyard P. Weight gain in smokers after quitting cigarettes: metaanalysis. BMJ. 2012;345:e4439.

19. Komiyama M, Wada H, Ura S, Yamakage H, Satoh-Asahara N, Shimatsu A, Koyama H, et al. Analysis of factors that determine weight gain during smoking cessation therapy. PLoS One. 2013;8(8):e72010.

20. Flegal KM, Troiano RP, Pamuk ER, Kuczmarski RJ, Campbell SM. The influence of smoking cessation on the prevalence of overweight in the United States. N Engl J Med. 1995;333(18):1165-1170.

21. Swan GE, Carmelli D. Characteristics associated with excessive weight gain after smoking cessation in men. Am J Public Health. 1995;85(1):73-77.

22. Williamson DF, Madans J, Anda RF, Kleinman JC, Giovino GA, Byers T. Smoking cessation and severity of weight gain in a national cohort. $\mathrm{N}$ Engl J Med. 1991;324(11):739-745.

23. Patel K, Hargreaves MK, Liu J, Schlundt D, Sanderson M, Matthews CE, Dewey CM, et al. Relationship between smoking and obesity among women. Am J Health Behav. 2011;35(5):627-636.

24. Healton $\mathrm{CG}$, Vallone $\mathrm{D}, \mathrm{McCausland} \mathrm{KL}$, Xiao $\mathrm{H}$, Green MP. Smoking, obesity, and their co-occurrence in the United States: cross sectional analysis. BMJ. 2006;333(7557):25-26.

25. Liu T, Chen WQ, David SP, Tyndale RF, Wang H, Chen $\mathrm{YM}, \mathrm{Yu} X \mathrm{X}$, et al. Interaction between heavy smoking and CYP2A6 genotypes on type 2 diabetes and its possible pathways. Eur J Endocrinol. 2011;165(6):961-967. 